\title{
Partnering in China: A Case History
}

\author{
Barbara Couture
}

Senior Vice Chancellor for Academic Affairs, University of Nebraska-Lincoln

$\mathrm{P}$ artnering with China to meet academic objectives is almost a given, although less than a decade ago it is unlikely that most American research universities would have made this claim. In this brief report, we outline reasons why it is crucial for them to do so, and cite particular reasons that lead the University of Nebraska-Lincoln to pursue academic partnerships with Chinese institutions, focusing on elements that have lead to our success, in particular, with $\mathrm{Xi}^{\prime}$ an Jiaotong University.

\section{Why China?}

China is the most rapidly changing economy in the world-a fact that no institution, private or governmental, can ignore. The social, political, industrial, and ecological impacts of China's rise are world-wide and affecting us nationally. In the summer of 2008, at the G-8 economic summit alone, news commentators who have generally focused on U.S. economic leadership were bubbling with claims that the summit simply was ineffective without China at the table. And, of course, expectations for China's leadership have heightened following Beijing's highly visible-and some would say unsurpassable-success with the summer Olympics.

In addition to national worries about China's dominance, in the U.S. each of our states has also taken notice of China's rise and, in some cases, this has led to economic growth for industries stoking China's economic engine. Nebraska is no exception; not only is
China a trade partner, but it also is one of the fastest growing importers of Nebraska products. Though our exports are small comparatively, they increased from \$51M in goods to China in 2000 to $\$ 187 \mathrm{M}$ in 2007 , making China the $4^{\text {th }}$ largest importer of Nebraska goods after Canada, Mexico, and Japan. Of interest to us at the university, Nebraska's top exports are in the areas of Processed Foods, Machinery Manufacture, Crop Production equipment, and Transportation Equipment-all industries which parallel expertise at the University of Nebraska in agriculture, biosciences, and engineering.

But beyond China's importance to our economy and its reliance on our research universities to fuel innovation, China poses tremendous potential as a source of new university students. With 1.3 billion residents, and $20 \%$ of the world's population, China's postsecondary education system cannot meet the growing demand for services; services that can be provided, in part, by American 
universities. Chinese universities are now at full-capacity, and the demand for college education is woefully unsatisfied.

Just $28 \%$ of qualified Chinese high school graduates can enroll in Chinese universities/colleges - there simply are not places for the rest. China, at present, has fewer than 1000 universities and 9.5 million potential freshmen. Only 2.7 million have hopes to enroll. Although universities are rapidly expanding on the mainland, the gap in demand and supply at this time poses a potentially huge opportunity for American higher education, especially for those universities in states where population is dwindling and concerns about future university enrollment dominate.

\section{And why not?}

Yet with such seemingly boundless opportunity can also come great risk. Higher education today is rife with examples of failure in China. In 2006, The Chronicle of Higher Education reported that more than 700 foreign academic programs were operating in China. Kermit Hall, interviewed for an article on the topic and who was, at the time, president of SUNY Albany, said prophetically about this boom in academic programming: "China is clearly the Klondike of higher education at the moment." The Chronicle reported then that both the demand for education and the potential for profit in China were enormous. Successful programs cited then included the University of Nottingham, the University of Maryland and UT-Arlington.

Two years later, The Chronicle presented a more sobering picture, reporting a near scandalous review of the Missouri State University partnership with Niaoning Normal University. MSU was unable to recruit professors from Missouri to teach in the branch campus they established, students who attended classes there were ill-prepared, especially in the English language, and cheating among students was rampant. In addition, the facilities at the institution were poor, and students reported typical classes of about 100 students with little interaction, many taught by distance education, with only a facilitator on site.

Much of the criticism of American academic programs in China was linked to inadequate investment. Faculty members hired to teach in the MSU program at Niaoning earned about $\$ 13,680$. By contrast, the U. of Nottingham's program in Ningbo paid professors $\$ 40,000$ a year, plus a housing allowance, a salary comparable to those we might expect for lecturers and some assistant professors in the United States. But aside from a lack of adequate investment, the MSU failure also illustrated a lack of articulation of the value, meaning, and purpose of the academic partnership, an articulation that we will argue here is crucial to success of programs established.

\section{What does it take to "partner"?}

Certainly adequate investment is important for any quality enterprise, but in the case of partnership programs equally important is a solid, open, and well-articulated partnership between the cooperating institutions. To illustrate this point, we focus here on two of UNL's marquee partnership programs with Xi'an Jiaotong University (XJTU):

- The UNL Confucius Institute offers Chinese language and cultural education to Nebraskans 
and serves as a cultural bridge for business and industry.

- Our partnership degree program with XJTU City College (an affiliate of XJTU) invites qualified selected students at XJTUCC to take 2 years at their home institution (XJTUCC), including English taught by a UNL faculty member and then transfer to UNL as 3rd year students, where they will complete their coursework and earn a UNL degree.

The success of both of these programs was born of our attention to the core meaning of "institutional partnership." For us at UNL it boils down to this principal: Collaborators work together; partners build together. Partnerships require complete trust and faith in the future success of both institutions through forwarding the partnership. Like happy marriages, good institutional partnerships require not only upfront work to ensure a happy union, but also attention paid to how partners are working together on a regular basis. Institutional partnerships also require deep "family" connections on many levels, from president or chancellor to chief academic officers; to research officers, faculty and support staff; and to public relations personnel, student affairs officers, and events staff. All personnel associated with partnership need to first and foremost understand their roles in securing the partnership; these individuals' commitment to those roles will assure that the partnership is institutionally grounded. And, like all happy partners, they also will feel committed to celebrating its success.
In pointing to our case study partnership with XJTU, we focus here on seven strategies that can lead to a partnership with a foreign institution that succeeds:

- Assure institutional compatibility

- Build on existing relationships

- Recruit institutional brokers

- Make and honor agreements

- Create a physical presence

- Develop a shared story

- Practice patience

\section{Assure institutional compatibility}

Both UNL and XJTU are similar, though obviously different. We house about the same number of students and we both are located in the middle of our nations. We share similar values: Love of farmland and agriculture-typical "midwestern" values for straightforward talk and hard work. Both institutions also share distance from the nation's capital. We were amused by a remark of XJTU's president, who, on a visit to UNL, remarked on our similar relationships to our nation's capitols-just as we feel some freedom from Washington's dominance being in the middle of America, they also enjoy a bit more relaxed atmosphere because they are far enough from Beijing! UNL and XJTU are both strong comprehensive research universities; they are national universities with strong regional presence and sensibilities. Also, similarly, both institutions have a research ambition to "catch up" to east coast universities (Harvard for us, Beijing $U$ for them). Noting these similarities has helped forge a common bond across institutional officers. 


\section{Build on existing relationships}

$\mathrm{Xi}^{\prime}$ an Jiaotong University was not a stranger to UNL. Individual faculty members had established research relationships with the university which had grown, in some instances, to study abroad programs for our students. Prior to establishing the Confucius Institute and our partnership degree programs we had sent students to study at XJTU in the summer, accompanied by professors in business and engineering, and several professors of engineering, business and math had on-going research relationships with colleagues at XJTU. In fact, it is these pre-relationships that have strengthened the partnership as we established new programs. Faculty and staff who travel to China often "hook up" with friends and colleagues of those who have made previous trips to the institution, widening the circle of those engaged in keeping the relationship strong.

\section{Recruit institutional brokers}

We cannot emphasize enough the importance of having colleagues aboard who have a personal commitment to securing the partnership and doing all things-big and small-to maintain connections between institutions. We established a "special assignment" post as Director of Chinese Initiatives for Dr. David Lou, a professor of Mechanical Engineering at UNL. Professor Lou was born in China, is now a U.S. Citizen, has resided in the U.S. for decades, and has a long and successful history as a professor and administrator at UNL. His passion for the projects, his knowledge of Chinese and Chinese culture, and his dogged enthusiasm has kept us on track. He served as an institutional advocate who understood how best to work with our partners and also how to make UNL's existing systems work with China. Furthermore, he apprised us of numerous important steps to establishing the relationship, including work with the Chinese embassy in America, contacts with specific administrative offices at XJTU and other Chinese universities, and protocol for visitations. When we established the Confucius Institute at UNL, Dr. Lou was our natural choice to direct the program.

Our chief partner institutions, XJTU, also has assigned superb "institutional brokers" who provide the same services to UNL. Susan Song, Associate Director of International Programs, and Zhenping Feng, Director of International Programs, and their colleagues at XJTU are our partners' "go to" folks for all matters of concern from drafting international agreements, to assuring that UNL colleagues and students visiting XJTU are safe, happy, and wellfed.

\section{Make and honor agreements}

Gone is the time when a simple Memorandum of Understanding was all we needed to be off and running in arranging faculty and student exchanges, filing away the fancy document signed with a flourish by chancellors and presidents. Although the traditional MOU that establishes a friendly relationship certainly plays an important part, increasingly agreements must cover much more if academic and research partnerships are to succeed. All agreements must be in writing and they must be thoroughly understood. But equally important, the agreements must point to mutual benefit of both partners. 
At UNL, we are now "rethinking" the way we handle international agreements, placing them into two categories: those which involve standard MOUs and often a limited relationship between a faculty member or a department and a researcher or a program at another institution, and those that are more complex, leading to-perhaps-joint degrees, technology transfer, or economic development. We are revamping our procedures for reviewing international agreements, expanding required reviews to include, in some cases, our business office, our technology transfer office, legal counsel, and others. And we have established an International Programs Advisory Committee which is charged to advise us on general criteria for establishing such complex relationships. For instance, we want deep partnerships to advance our core values, to increase academic quality, and to increase our visibility as an international university. In the case of academic programs, we want them to increase and enhance student enrollment; our research programs should advance research quality and opportunity for economic investment.

For both the Confucius Institute and the Partnership Degree program we drafted multiple agreements, first outlining a vision for the programs and later going into finer detail. These agreements were reviewed by our international programs office, our deans, vice chancellors, student affairs officers, and other officers as appropriate. At XJTU they were reviewed by their international programs office, by their academic officers and president, and, in the case of the Confucius Institute, by Hanban, the Chinese government educational agency promoting Chinese language and culture, and the Chinese embassy.

The agreements had to address mutual expectations on some fairly fundamental issues, such as budget and who pays for what services, timelines for delivery of students or programs, and ways to "exit" the agreement, if necessary. At UNL always the expectation was for deep connection of the partner institutions with academic programs, and XJTU followed suit. We have found that we go back to these initial agreements again and again when we have questions about what we have invested or what expectations may or may have not been met.

\section{Create a physical presence}

For both of our signature programs with XJTU, our primary investment is at UNL, but we have a physical presence at both institutions. For the partnership degree program, we are recruiting freshman and sophomore students at XJTU City College, in China, who will come to UNL in their Jr. year. XJTU CC is an affiliate institution with XJTU; it enrolls students who have applied to XJTU and for whom there is not room in programs offered on the main campus. The primary UNL contacts for our student recruits at XJTU CC are an English instructor, hired and paid by UNL, who receives two weeks of intensive training at UNL on our systems and procedure and an office manager, who resides in a program office on the XJTU City College campus. Both personnel are crucial to success of the program: Our English instructor was 
hired in an international search and we were fortunate to find a qualified candidate who had attended UNL and knew and loved Nebraska. Our on-site manager has become one of our greatest recruitment assets. We initially thought we'd rely on our English instructor to advise our students, but her office is distant from our institutional office space, intentionally so, as we felt it important for her to be located with other English instructors on the campus. Our highly capable and enthusiastic UNL office manager soon became the go-to person who served as a point of contact for students, potential students, parents, UNL and XJTU. She has arranged parties for our students, helped them make connections by internet to our campus, and developed a sense of "school spirit" among the recruiting class. This summer we invited her to spend three weeks on the UNL campus where she became more involved with student affairs personnel and more knowledgeable about life in Lincoln.

Although a permanent UNL office space would seem not be absolutely necessary for this program in China, it has become so. Our UNL office is the Nebraska home for these students before they come to the U.S. Our office space in $\mathrm{Xi}^{\prime}$ an is filled with UNL flags, posters, photos, and a good internet connection where students can view our website. Although UNL paid for incidentals, our Chinese partners have provided the space, furniture, computers and phone lines.

At UNL, we have created a dedicated space for our Confucius Institute, with a front office, an office for our Director, Dr. David Lou, two faculty offices, a conference room and a library. As part of our Confucius Institute grant, Hanban has provided us with an extensive library of Chinese language books and XJTU has generously provided artwork for the space.

Most important are frequent visits by university officers and faculty to each institution. When this article is printed, I will have made my fourth visit to China in two years, and my third to XJTU. Dr. Lou visits nearly monthly, and more than a dozen other UNL representatives have visited, including a political science professor who, with her family, is doing a sabbatical in $\mathrm{Xi}^{\prime}$ an; the chancellor, our vice chancellor for research and economic development, numerous faculty and deans, admissions representatives, and others. We bring UNL students to $\mathrm{Xi}^{\prime}$ an each summer for cultural programs and classes in business and engineering, and these students are encouraged to meet with our XJTU CC student recruits and give them a personal, face-to-face introduction to student life at UNL.

Our XJTU partners are equally committed to a physical presence, and bring XJTU students to UNL for English classes and cultural tours. Susan Song has spent several months with us, assisting with summer programs for our Confucius Institute and learning American administrative practices; and we have with us year-round two Chinese teachers from XJTU who teach non-credit Chinese language classes for children and adults, associated with Confucius Institute.

For our Chinese partners and for us, USA/China has almost become a 
"commute." We are careful to plot out the purpose and outcomes of all of these trips, and, too, we are mindful of our travel budget. That being said, we cannot over emphasize the importance of this kind of investment in mutual exchange to the success of the partnership.

\section{Develop a shared story}

UNL and our Chinese partners have shared expectations and goals, articulated up front, which continue to help drive decision making. Our immediate goals were to take advantage of the Chinese Government's eagerness to launch Confucius Institutes and to increase our undergraduate student enrollment through a partnership degree program. We worked consistently to achieve these mutual goals. Furthermore, we developed a common narrative about what was distinctive about our partnership, which highlighted the detailed involvement and commitment of university officers, faculty members and staff at several levels in the organization, from the moment of deciding to partner to developing the full-fledged programs of the Confucius Institute in Lincoln whose programs serve UNL students and Nebraska communities, and degree completion program for Chinese undergraduate students coming to UNL in their junior year to complete a variety of majors.

We found it very important to celebrate together beginnings and anniversaries: The dedication event for our Confucius Institute was enriched by a group of 18 student musicians from Xi' an Jiaotong University, who played a concert of traditional Chinese music the day before the event and also played at the event. As our first year progressed, we used several on-going occasions to feature the partnership. For instance, many faculty and administrators were accustomed to attending UNL's annual Chinese New Year festival, sponsored by our Chinese Student Association, which typically sells out months in advance and attracts 800to 1,000 people. We linked this event to the Confucius Institute, and as chief academic officer, I opened the event, speaking a few words of Chinese which I learned in one our non-credit courses offered by the UNL CI. This small gesture was received with overwhelming enthusiasm. A University Communications video production team taped the event and created a video segment for our "Real Nebraska" series, which is an ongoing student recruitment project. The resulting segment was downloaded to computers used by our students at XJTU CC and received with great enthusiasm by our student recruits there.

We also have used numerous occasions to feature our shared values, and, too, to demonstrate that we were forming a "mutual admiration" society, an important step toward stabilizing the partnership. Here are some UNL examples: When attending the $2^{\text {nd }}$ Annual Confucius Institute conference, held in December in Beijing, we met our partners there and attended every event with them. We also took the opportunity while there to visit XJTU, several hundreds of miles away. At the conference, officials from other institutions and Hanban remarked on the visible strength of our partnership, something that wasn't as apparent 
among other university representatives and their Chinese partners. The following February, UNL's Chancellor Harvey Perlman invited President Zhen of XJTU to give a talk on higher education at UNL, to which we invited all deans, Vice Chancellors, faculty and students to attend; similarly, XJTU has invited me and Chancellor Perlman to attend XJTU and where we will speak to their faculty on higher education administration. (Incidentally, Chancellor Perlman challenged President Zheng to a ping pong match-little does he know that Perlman was a high school champion!)

Finally, we have taken numerous opportunities to develop and publicize shared leadership. For the UNL Confucius Institute we have developed a shared governing board, including the UNL chancellor and XJTU President, chief academic officers, our director and associate directors, and external supporters; for the partnership degree program we have developed a partnership team of university personnel in the U.S. and China who keep in contact by e-mail and a blackboard site. We have developed a website for the Confucius Institute and frequently publish updates on on-going activities in newsletters campus-wide and in the Office of Academic Affairs; XJTU conducts a series of similar publicity efforts on their campus and the campus of XJTU City College as well.

\section{Practice patience}

Team efforts require patience, and international partnerships are no exception. Along with the usual challenges of working together, we have had various technical difficulties that have worn the patience of our professional and support staff. Visa difficulties are the norm: For the opening ceremony of the Confucius Institute, the student band had difficulties obtaining their U.S. visas and also were delayed due to weather/airline problems.

We have had difficulty getting work visas for on-site staff, as well; in addition, these matters have strained the patience of our international programs staff. We have been lucky to find excellent teachers, both to send to China, and to teach Chinese at UNL. Professor David Lou was a key player in ensuring that this occurred. We extensively interviewed all candidates on both sides. In the case of the Chinese teachers who came from XJTU to teach here, Professor Lou watched them teach Englishspeaking students in China before recommending them to us.

And finding suitable housing for staff is also difficult: Again, our institutional broker, Professor Lou, was of invaluable assistance. He secured offcampus housing for our Chinese teachers in Lincoln and helped secure suitable accommodations for our English teachers in China as well. Having someone to really pay attention to these comforts for visitors here and abroad was crucial.

For the partner degree program, we had assumed we would have syllabi translated into English to work from. Although our partner institution worked diligently to produce them, inconsistency in format and various translations for a single course title (e.g., Are English I, Freshman English, Firstyear English all the same?) have tripped us up. And, too, staff have felt burdened 
by the extra attention required to address these details. Group meetings in which we have stressed the importance of all of us committing to the success of the partnership have helped keep staff on course.

Communications of all sorts have required interminable patience. We discovered that our first and second year students in China are not allowed internet access in their dorms. Our office manager there has helped them find access in labs and other sites. Although the internet can be "immediate", the 13hour time difference is frustrating when decisions must be made quickly. Also, the detail required for proper attention to ceremony and ritual is significant and necessary to keep communications friendly and on track. Our Chinese partners were much more attuned to this than we were; we have had expectations for social involvement that surprised us. Each UNL staff member who has visited our partner institution has been asked to deliver numerous little "talks" and presentations on how things are done at our university, for instance, in addition to attending a seemingly endless spate of banquets and luncheons. And we make the most of genuine and intense social interactions. Face to face time is critical and needs to be maximized - and this goes a long way toward easing strained relationships. When we were wooing Hanban to win a Confucius Institute for UNL, we wined and dined, but we also took the time to express our genuine commitment to each person who visited us from the Chinese embassy, XJTU, and Hanban. The Hanban representatives' officials from the Chinese embassy were impressed by this, and, frankly, we moved ahead of a competition on the list directly because of the success of these interactions.

At UNL, we have involved everyone from the Chancellor to the Admissions Office to the Budget office to "make things work." We have found it necessary to have involved from the getgo folks in the institution who understand how to recruit, what the needs of undergraduate students are, who can plan events, who have publications in hand; equally important are ESL specialists, career services personnel, writing specialists. As we have said several times over, the partnership has been an exercise in team-building.

Paying attention to costs is also critical. The declining dollar has meant that things are costing more than we anticipated and budgeted. For our partnership degree program, we are not expecting a "payout" or even breaking even for two to three years. Yet at the same time, unexpected benefits have developed. What started as an academic partnership is now extending to a research partnership. In October 2008, we hare holding a two-day conference at XJTU featuring research faculty from both institutions who will talk together about ways to collaborate and partner to secure national and corporate funding for their international research.

\section{Conclusion}

Partnering with China can be rewarding and beneficial for research universities here and in China. The benefits to UNL have been visible and immediate. We have extended cultural diversity on our campus, adding a Confucius Institute that provides non- 
credit culture and language classes. We are in the process of adding a China Studies concentration to our curriculum, and we have greatly expanded efforts to engage in international activities-we are quickly becoming a global campus. The presence of the Institute also has led to our revival of Chinese language study for credit. When all our partnership degree plans with XJTU CC are fully realized, we will add 500 new Chinese undergraduate students to UNL each year. Because we are under capacity in our undergraduate operations, this means a substantial increase in tuition revenue as well as an economic boost to Lincoln. We have now institutionalized the partnership, involving nearly every office of the university, insuring that it will grow and outlast the original players. And we have significantly increased faculty and student interest in study abroad to China; four separate trips were scheduled for faculty and students in 2008 and more are on tap. Furthermore, we have extended the academic partnership with XJTU, using similar methods and procedures, to another major Chinese university near Shanghai and have started a research partnership there as well.

This case study, as a single instance of collaboration, has been filled with anecdotal detail, but, as we have said many times here, it is attention to this detail that has insured the success of our university-to-university partnership. We hope our experience provides useful information for others who hope, like us, not merely to collaborate but also build together through international partnership. 